\title{
OCEANS AND DROUGHT
}

\author{
Martin Hoerling ${ }^{(1)}$ and Siegfried Schubert ${ }^{(2)}$ \\ ${ }^{(1)}$ NOAA Earth System Research Laboratory, Boulder Colorado,USA, E-mail: martin.hoerling@noaa.gov \\ ${ }^{(2)}$ NASA Goddard Space Flight Center, Greenbelt Maryland USA, E-mail: siegfried.d.schubert@nasa.gov
}

\begin{abstract}
Evidence for the ocean's role in driving precipitation variability is presented. We begin by exploring the causes for seasonally recurring dry and wet seasons, known as the monsoons in tropical latitudes, and assess the role played by the seasonal cycle of the ocean's response to solar insolation. We next examine the ocean's role in the year-to-year and longer-term disruptions in normal rainfall patterns, conditions typically referred to as drought and pluvial. We focus on studies of sea surface temperature (SST) impacts on several historical droughts and draw assessments of ocean observing system requirements that could facilitate drought early warning. These must be viewed as preliminary and tentative given the nascent stage of our knowledge of the ocean stemming partly from the paucity of climate-quality ocean observations. A critical and quantitative evaluation of the importance of subsurface oceanic processes through which sea surface temperature conditions may develop and affect the risk of drought on decadal time scales, for instance, is not yet possible. Further modeling studies are also required to better identify those particular regional features of sea surface temperature anomalies that are most relevant for drought prediction.
\end{abstract}

We highlight three particular aspects of the relationship between oceans and drought. The first is the link between the seasonal pulse of monsoons and the seasonality of SSTs, and we show that the north-south migration of monsoon rains is strongly tied to the ocean's response to the annual march of the Sun. The second is the link between interannual-to-decadal droughts and anomalous ocean states. It is shown that SST variability enhances drought variability over most land areas within $40^{\circ} \mathrm{N}-40^{\circ} \mathrm{S}$, indicating that the more extreme climatic states of precipitation arise partly as a consequence of sea surface temperature variability. We demonstrate this link for two widely studied historical events---- the mid-20 $0^{\text {th }}$ Century droughts over North America including the Dust Bowl and the great Sahelian drying in the later half of the century. A third feature concerns the link between the oceans and drought in a warming climate. Ocean temperatures have risen over the warmest portions of the tropical oceans, likely due to the effect of increasing greenhouse gases. The effect of such sea surface temperature trends on regional rainfall trends during 1977-2006 is discussed.

\section{EARTH'S DRY AND WET SEASONS}

The annually recurring dry and wet seasons represent the most dramatic regular pulse of Earth's climate, and this natural rhythm affords valuable clues on the link between oceans and drought. The global pattern of boreal summer minus winter rainfall captures the essence of this pulse---- wet conditions prevail over the Sahel, India, Southeast Asia, and Central America when the Sun is at its zenith in the Northern Hemisphere, while dry conditions prevail over southern Africa, northern Australia and the Amazon (Fig. 1).

Results in Fig. 1 are based on climate model simulations using specified observed seasonally varying sea surface temperatures and solar insolation, and the modeled rainfall seasonality are in excellent agreement with observations. The seasonal cycle of rainfall simulated in the same climate model but in which specified SSTs (Sea Surface Temperatures) have no seasonal cycle (i.e., the only seasonal forcing is the seasonal varying incoming solar radiance) is compared to that occurring in the parallel runs using realistic seasonally varying SSTs. These results, shown in Fig. 2, indicate that the swing between wet and dry seasons in the tropics is strongly driven by SST seasonality. This is true for monsoons over oceanic regions, including the Maritime continent where a controlling effect of underlying SSTs is not surprising, but also for terrestrial monsoons including India, Central America, northern Australia, and the Amazon region. These experiments indicate that the oceans play a major role in the monsoon's pulse, and that the annually recurring wet and dry seasons are not responding to the seasonal cycle of warming and cooling of land temperatures by direct solar forcing alone.

\section{INTERANNUAL AND DECADAL DROUGHTS}

The seasonal cycle of dry and wet seasons provides a valuable test-bed for learning about the ocean's role in climate, yet societal vulnerabilities are more intimately tied to disruptions in the march of the seasons. When this involves a failure of normal seasonal rains, the event is conventionally referred to as drought, and the resulting moisture deficit can exceed demand over an extended period. In light of the ocean-monsoon link for the seasonal cycle that was illustrated above, it is reasonable to expect that disruptions in the normal seasonal cycle of SSTs could likewise disrupt moisture balances. There is ample evidence from case studies, 


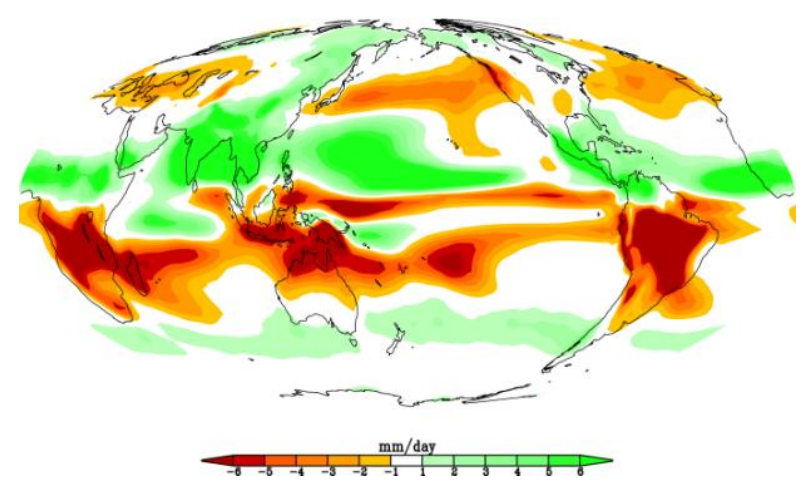

Figure 1. The seasonal cycle of rainfall (July/Aug/SeptJan/Feb/March) based on simulations of a climate model using realistic observed seasonally varying sea surface temperatures. Green (red) indicates regions of wetter (drier) boreal summer (winter) climate relative to boreal winter conditions.

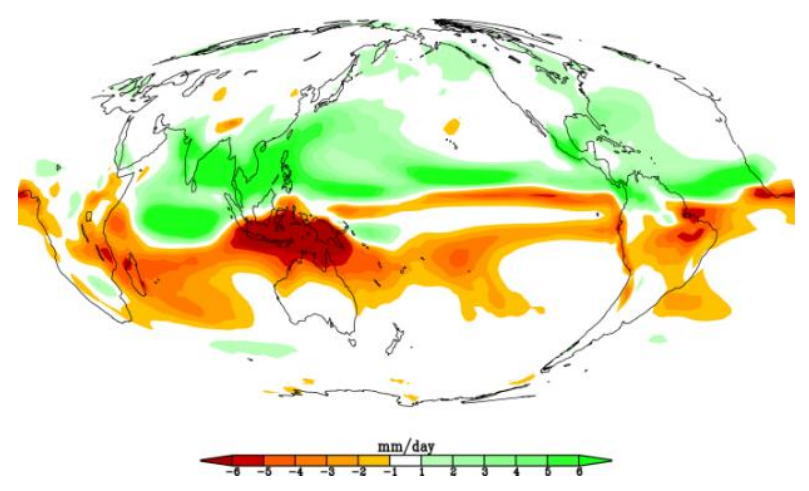

Figure 2. The difference in seasonal cycle of rainfall (July/Aug/Sept-Jan/Feb/March) between simulations of a climate model using realistic observed seasonally varying sea surface temperatures and parallel simulations in which SSTs have no seasonal cycle. Green (red) indicates regions where the SST seasonal cycle drives a wetter (drier) boreal summer (winter) climate compared to runs having no SST seasonal cycle.

several of which are discussed in more detail below, that reconcile interannual to decadal drought events with a region's sensitivity to anomalous sea surface temperatures.

As a prelude to examining historical drought events at regional scales, we first explore the overall precipitation sensitivity to SST variability during the last century as a whole. This is done by comparing the year-to-year variation in precipitation in climate simulations that are subjected to the specified observed variability in global SSTs during 1901-2000 (so-called AMIP (Atmospheric Model Intercomparison Project) experiments) to control simulations of the same models in which SSTs only undergo repeating climatological seasonal cycles. Precipitation in the latter experiments vary from yearto-year via internal atmospheric processes alone, and also due to the coupling of the atmosphere and land, whereas SST variations can provide an additional source for rainfall variability in the AMIP experiments. The results in Fig. 3 reveal significant enhancement of precipitation variance due to SST fluctuations over the world oceans. In particular, precipitation variance is more than doubled over the Maritime Continent, equatorial South America and portions of India. These are among the regions that have particularly strong sensitivity to the El Niño/Southern Oscillation (ENSO) phenomenon when droughts are often widespread over tropical land areas as has been shown in numerous empirical studies (e.g., Ropelewski and Halpert 1987; Ropelewski and Halpert 1989; Kiladis and Diaz 1989; Lyon 2006). Likewise, many other continental regions between $40^{\circ} \mathrm{N}-40^{\circ} \mathrm{S}$ experience an increase in precipitation variability on the order of $10 \%-25 \%$ due to the SST variability.

A critical and still open question is which SSTs are principally responsible for the increased precipitation variance over the continents. Considerable progress has been made in demonstrating the essential role of a tropical Pacific Ocean observing system for seasonal rainfall predictability that is linked with ENSO [see McPhadden et al. (1998) for a summary of the progress in developing a tropical ocean-global atmosphere observing system; see Quan et al. (2006) for an assessment of the oceanic sources for skill in U.S. seasonal precipitation forecasts]. Yet ENSO is probably only one of several sources for the SST induced rainfall variability in Fig. 3. Modeling studies indicate that Indian Ocean SSTs affect the seasonal rainfall over the Indian and Maritime Continents (Annamalai et al. 2005), and likewise the rainfall over tropical Africa (Palmer 1986; Goddard et al. 1999). It has also long been known that tropical Atlantic SSTs exert a strong effect on seasonal droughts over portions of Brazil including the Nordeste region, and over sub-Saharan Africa (Lamb 1978, Hastenrath 1984; Hastenrath and Wolter 1992). To date, comprehensive predictability studies of the ocean conditions involved in such impacts have not been undertaken, in part owing to the lack of an advanced climate-length ocean observing system in either the tropical Atlantic or the Indian Ocean that is commensurate with the TAO/TRITON (Tropical Atmosphere Ocean/Triangle Trans-Ocean Buoy Network) array in the Pacific.

Only recently have century-long, large ensemble modeling studies been conducted that are suitable for addressing ocean-drought links on decadal and longer time scales, and these have provided exciting new indications for the ocean's role. Two iconic U.S. drought events of the last century span the Dust Bowl era of the 1930s and the comparably severe drought during the 1950s. These affected different geographical 


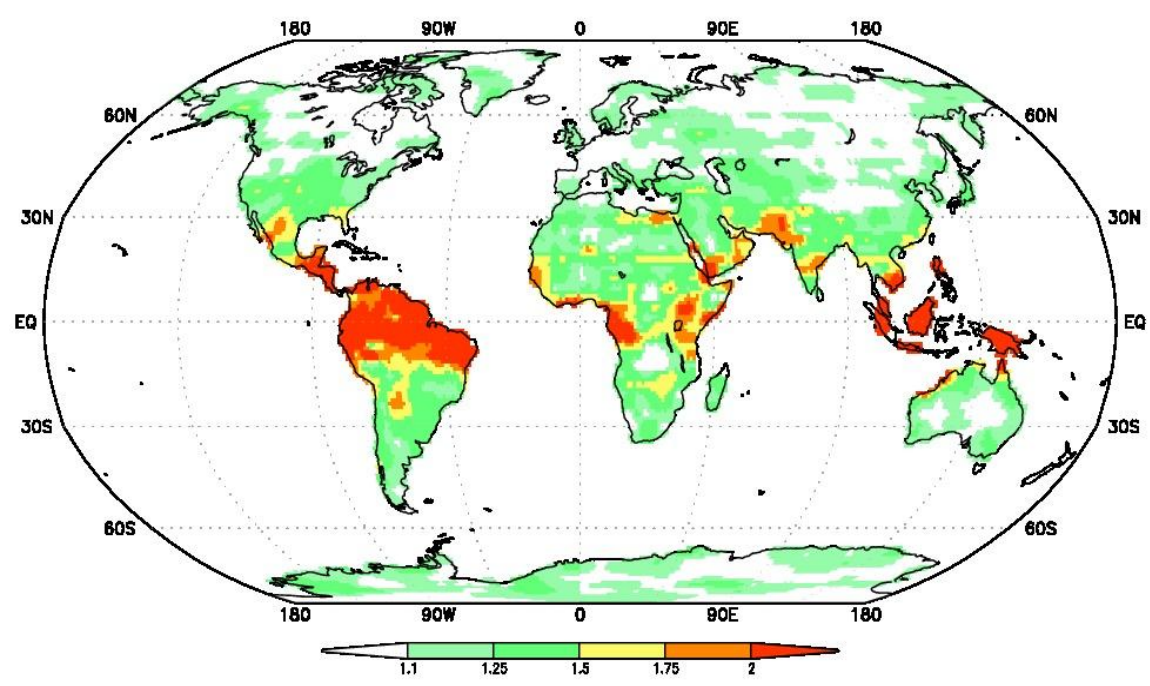

Figure 3. The ratio of variance of annual standardized precipitation in a climate simulation forced with observed interannual SST variations of 1901-2000 to that occurring in the same model using climatological seasonally varying SSTs only. Colored areas indicate where precipitation variance is enhanced, with red shades denoting a more than doubling of variance.
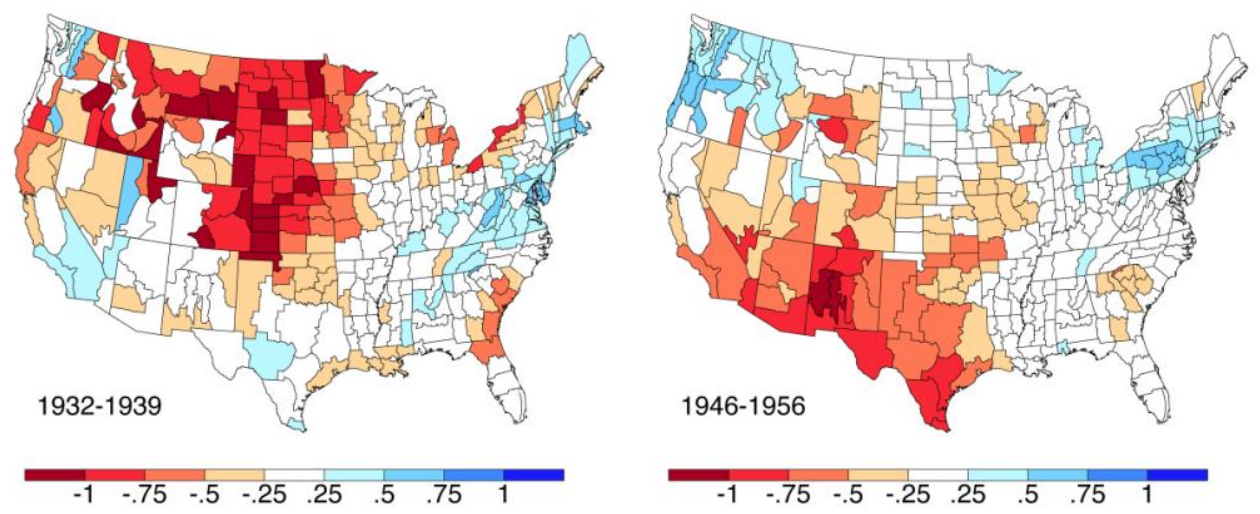

Figure 4. The observed standardized precipitation index (SPI) averaged for 1932-1939 (left) and for 1946-1956 (right). Red (blue) shaded regions indicate reduced (increased) precipitation during these epochs. Note that the Great Plains droughts of the 1930s and 1950s occurred over different geographical regions.

and also whether different SST conditions may have operated so as to generate these different drought footprints, one over the Northern Great Plains during the 1930s and the other over the Southern Great Plains during the 1950s.

The SST conditions during these two periods shared several common features, including tropical IndoPacific coolness and North Atlantic warmth. Yet, uncertainty remains as to the details of SST forcing during the Dust Bowl era in particular, a situation that requires both careful reanalysis of available historical marine data and re-simulation of that period when new SST information (and climate models) become available.
Another factor that must be considered when trying to understand the two great U.S. droughts of the $20^{\text {th }}$ Century is the role of the seasonal cycle. Figure 4, which illustrates annual mean decadally averaged anomalies, obscures one of the major distinctions between these two droughts, namely that the Dust Bowl era event was more a "warm season" drying while the 1950 s event was more a "cold season" drying (see Schubert et al. 2004b). Analysis of historical observations for the entire $20^{\text {th }}$ Century suggests that the North American rainfall response to cold tropical Pacific SSTs varies considerably from one season to another (Fig. 5). These analyses indicate that details in the temporal variability of SST anomalies could have 


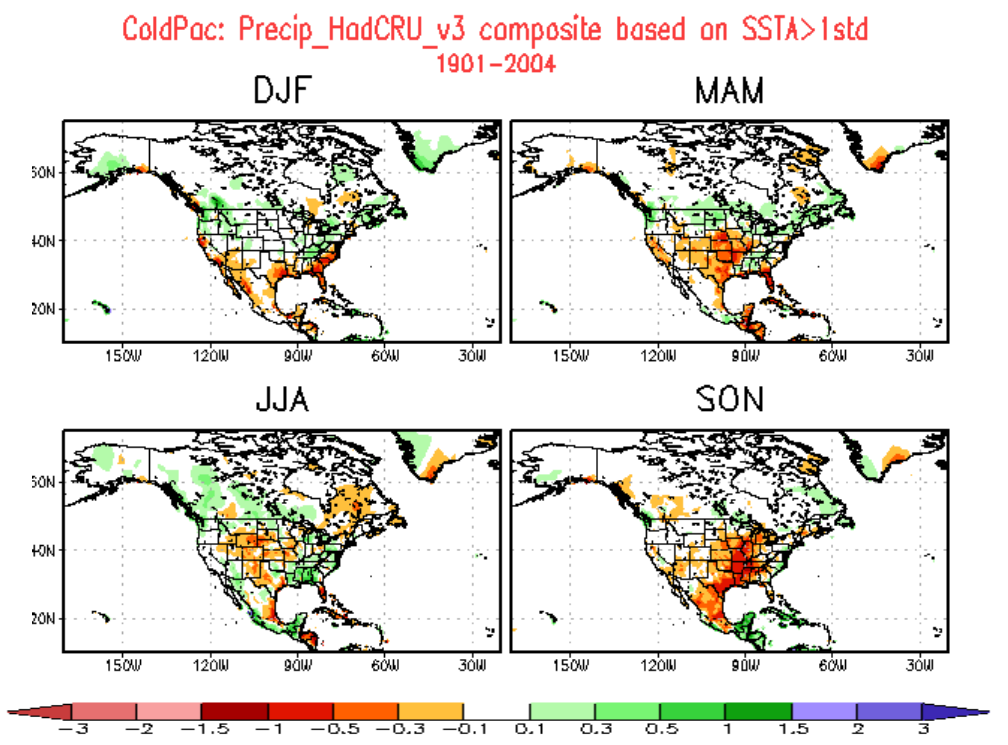

Figure 5. Composites of HadCRU (Hadley Climatic Research Unit) precipitation anomalies based on all years during the period 1901-2004 in which the ENSO-like Pacific SST pattern (see Schubert et al. 2009) had values less than -1 standard deviation (corresponding to a cold central and eastern tropical Pacific). Units: mm/day.
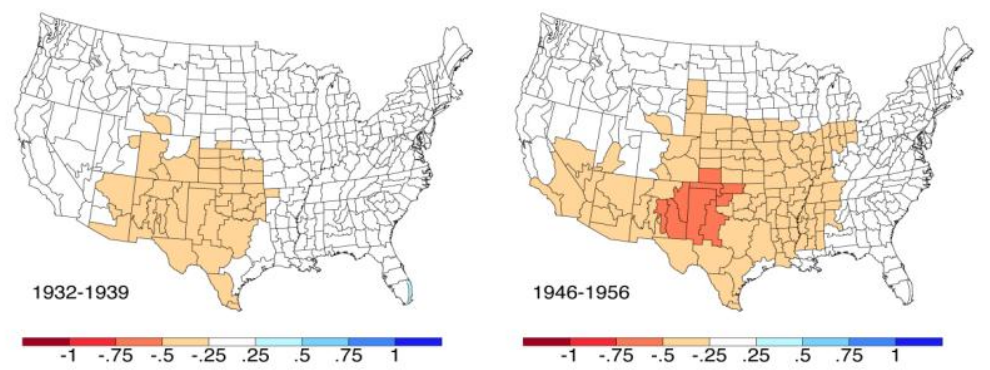

Figure 6. The simulated standardized precipitation index (SPI) averaged for 1932-1939 (left) and for 1946-1956 (right). Red (blue) shaded regions indicate reduced (increased) precipitation during these epochs. Results are based on a 40-run average of atmospheric GCM (General Circulation Model) simulations using three different models. Note the very similar patterns of Great Plains droughts of the 1930s and 1950s occurring in the GCM simulations

material consequences for drought impacts. For instance, interannual cooling events in the tropical Pacific associated with ENSO typically exhibit peak SST anomalies from Fall thru Winter, whereas multidecadal cold conditions linked to the PDO (Pacific Decadal Oscillation) tend to have appreciable SST forcing in all seasons. The correlations in Fig. 5 imply that materially different drought patterns could thereby emerge under the influence of interannual versus decadal SST forcing.

A strategy to test the efficacy of the ocean's role, and to verify cause-effect links, is to force atmospheric climate models with the observed SSTs for the long historical period and assess drought occurrences using ensemble methods that facilitate signal-to-noise diagnosis. The first such study based on a particular atmospheric model found that several key aspects of the temporal history of drought in the Great Plains during the $20^{\text {th }}$ Century are reconcilable with slow fluctuations in global SSTs (Schubert et al. 2004a, b). A similar robustness to the SST sensitivity of historical droughts was subsequently confirmed using another model, and for additional U.S drought cases that spanned the latter half of the $19^{\text {th }}$ Century (Seager et al. 2005). A third investigation combined the simulation data from the aforementioned studies with a new set of ensemble model simulations, and focused on the question of whether different ocean forcings could explain the marked regional differences between the 1930s and 1950s drought events (Hoerling et al. 2009). The results indicate that a robust pattern of U.S. drought emerges in response to ocean conditions of the 1930s and 1950s (Fig. 6) that is focused on the southern Great Plains, a region that resides within an epicenter of potentially predictable drought for which an ocean observing system could constitute a drought early warning system. 
The results of studies on the Dust Bowl lead to a more subtle picture of causes, and provide a nuanced view of the role of oceans compared to the view of the ocean's role in the 1950s drought. There is the issue of a seasonally varying response of North American drought to cool tropical Pacific conditions (see Fig. 5) which must be balanced against the considerable uncertainty in our knowledge of SST conditions during the 1930s. The scientific arguments on the ocean's role during the 1930s are not of a kind to be resolved by the available observations at this time. An accumulation of new ocean data and improved analyses in the future could provide important new evidence to advance our understanding. Nonetheless, there are a number of problems in any picture seeking to isolate the ocean's role in the Dust Bowl from other compounding and potentially interrelated factors. One is the danger of underestimating the ocean's role when only a modest SST-induced drying may be sufficient to initiate an appreciable positive soil moisture feedback (e.g., Koster et al. 2004) and other land surface interactions including aerosol effects (e.g., Cook et al 2008), And, despite what emerge as being large scale footprints of dryness during decadal droughts, their development and maintenance can depend upon short time scale and small spatial scale processes (e.g., meso-scale convective systems over the Great Plains through which much of the warm season rainfall is delivered, moisture transports in low level jets, seasonally varying SST sensitivity and land surface feedbacks). Ongoing development of climate models that realistically represent the spectrum of physical processes, which matter for drought, is thus essential for advancing our understanding of drought predictability.

A recent study conducted by the U.S. Climate Variability and Predictability (CLIVAR) working group on drought involved a systematic multi-model analysis to understand the uncertainties associated with the impact of ocean surface temperature forcing on drought (Schubert et al. 2009). Of particular interest to the question of requirements for an ocean observing system, the team of scientists explored the sensitivity of precipitation to recurring patterns of SST variations during the $20^{\text {th }}$ Century in different ocean basins. The study also addressed the role of SST conditions that reflect different time scale fluctuations in the oceans, including ENSO on interannual time scales, and the Pacific-Decadal Oscillation (PDO), the Atlantic multidecadal Oscillation (AMO), and the non-stationary trend component of global SSTs. The extensive data sets generated by the project are still under scrutiny, though for U.S. drought concerns the initial results establish a robustness of southern Great Plains drought sensitivities to cold phases of the tropical Pacific ocean, stemming from either La Niña on the interannual time scale or the negative (tropical cold phase) of the PDO on decadal time scales. Whereas the impact of AMO
SSTs appears to be less significant, the models were found to be in agreement that the combined impact of warm states of the North Atlantic Ocean and cold states of the tropical Pacific Ocean maximizes the overall drought signal for annual mean, continental averaged U.S. precipitation.

One of the many complicating factors in understanding decadal variability is distinguishing drought sensitivity to ocean conditions that evolve via natural coupled ocean-atmosphere variability from drought sensitivity to progressive changes in oceans related to anthropogenic forcing. The notion of a so-called "perfect ocean for drought" (Hoerling and Kumar 2003) has been raised in an attempt to understand a multi-year period of widespread NH subtropical-midlatitude drought. This event appeared to combine elements of naturally occurring cold tropical Pacific SSTs (related to a protracted La Niña) with unusual warmth of the Indowest Pacific Ocean that had been developing since the late 1970s. Both conditions enhanced the zonal contrast of SSTs across the Indo-Pacific basin, and may have caused a commensurate enhancement of widespread drought risks.

The Sahel drought during the latter half of the $20^{\text {th }}$ Century also illustrates a potential interaction between natural and anthropogenic components of ocean conditions. Giannini et al. (2003) provided the first evidence that the multi-decadal drying trend during the Sahel July-September seasonal monsoon season was consistent with a sensitivity to global SST variability. Subsequent model studies using multiple GCMs (General Circulation Model) and employing much larger ensemble sizes confirmed these initial results. For example, Fig. 7 shows the remarkable agreement between the observed 1950-1999 rainfall trends derived from the diagnosis of 80 simulations, using 5 models each forced with global SSTs for 1950-1999 (from Hoerling et al. 2006).

An ongoing scientific discussion is which regional SSTs were most instrumental in causing the $20^{\text {th }}$ Century rainfall decline over the Sahel, and whether the SSTs were attributable to natural coupled variations alone. It is has been long known that Sahel rainfall is sensitive to a worldwide pattern of sea surface temperature conditions ---statistical analysis of the relation between Sahel rainfall and an index of the interhemispheric contrast in SSTs reveals a strong relation on annual to decadal time scales (Folland et al. 1986). The prolonged drying of the Sahel after the 1950s occurred in unison with a cooling of $\mathrm{NH}$ (northern hemisphere) SSTs compared to the SH (southern hemisphere) SSTs (the latter including the Indian Ocean). One element of this pattern, to which Sahel rains are sensitive, was the cooling of the subtropical North Atlantic which likely resulted mainly from natural variability (e.g., 
Observed JAS

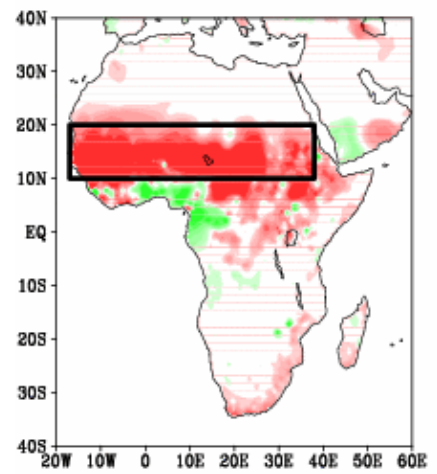

Simulated JAS

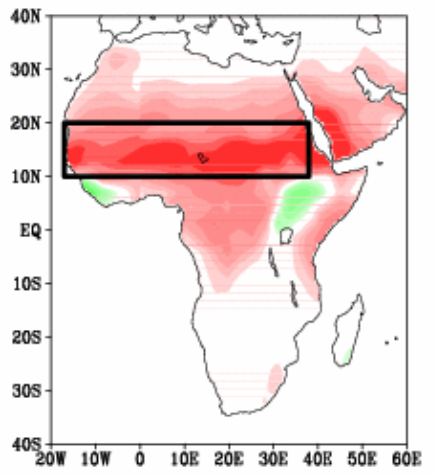

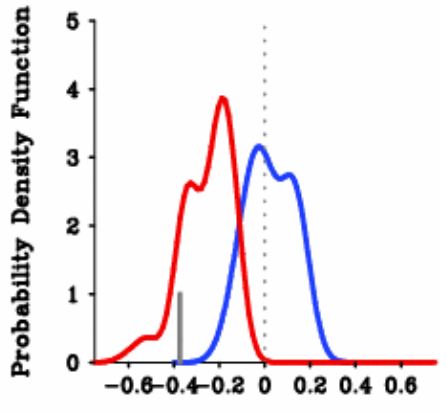

Fraction of Climatology

Millimeters

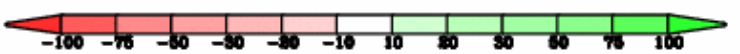

Figure 7. The observed and simulated 1950-1999 trends in July-September seasonal African rainfall. The right side panel illustrates the probability distributions of 50-yr rainfall trends for 1950-1999 occurring in individual members of the 80-run ensemble of SST-forced AGCMs(Atmospheric General Circulation Models (red) and also in individual members of a 15-run set of unforced coupled ocean-atmosphere model simulations.

Annual Sea Surface Temperature Trend

OBS

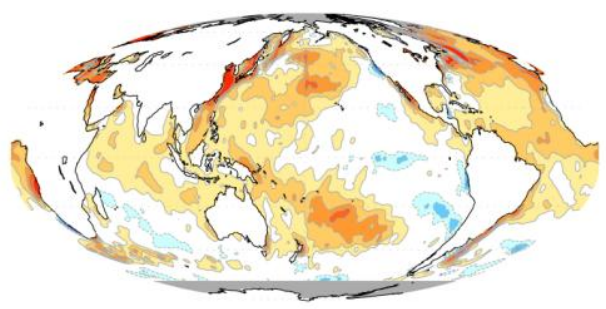

CMIP
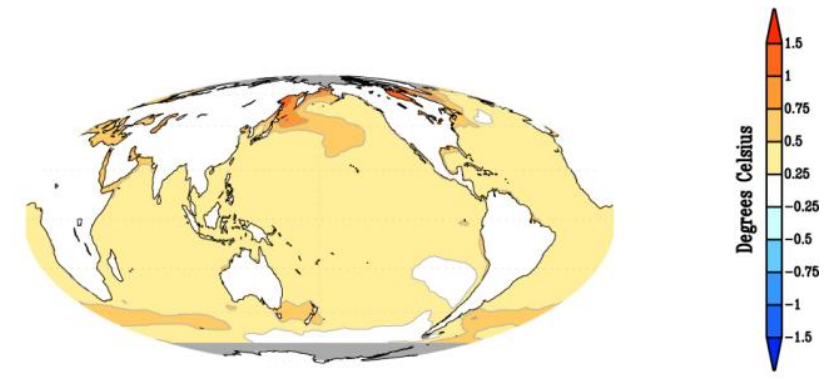

OBS-CMIP

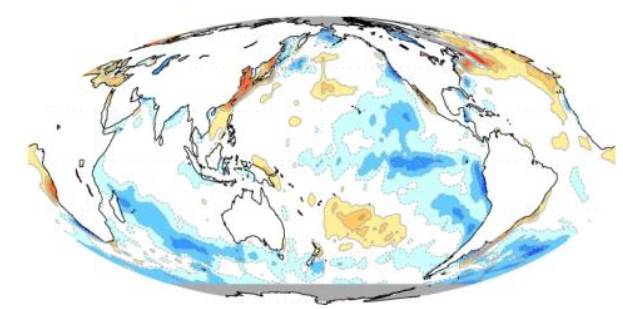

Figure 8. The 1977-2006 trend in annual observed sea surface temperatures (top) and CMIP3 (Coupled Model Intercomparison Project Phase 3) simulated sea surface temperatures. Trend toward warmer (colder) SSTs are indicated by red (blue) shades. The difference in 30-yr trends (OBS minus CMIP) is shown in the lower panel. Simulations are based on the average of 21 CMIP3 models that were forced by the observed GHG and aerosol variations from 1977-1999, and by the SRES A1B (Special Report on Emissions Scenarios) emissions scenario for 2000-2006. 
Hoerling et al. 2006). However, a warming of the Indian Ocean during this same period has also been proposed to have contributed to Sahelian drying, the latter SST change likely resulting from anthropogenic forcing (e.g., Gianini et al. 2003; Bader and Latif 2003; Hoerling et al. 2006).

\section{DROUGHT IN A WARMING CLIMATE}

Ocean observations need to be of climate quality in order to support efforts at detection and attribution of anthropogenic forcing, including to support capabilities for distinguishing the ocean's response to external forcing from its internal variations. As an indication of the fidelity required of ocean observations, we consider a recent study of ocean surface temperature changes and their impact on regional droughts for the period 1977 2006 (Hoerling et al. 2010). Since 1977, virtually all oceans have warmed, with the notable exception of the tropical and subtropical east Pacific (Fig. 8, top). It is in this latter region where the CMIP3 ensemble mean simulated SST change due to GHG (Greenhouse Gas) and aerosol forcing deviates most appreciably from observations. It is possible that this difference may have resulted from an unusually strong case of internal multidecadal variability (e.g., Wang et al 2009). In so far as no single CMIP3 simulation of this period generated a cooling as strong as observed, the study of Hoerling et al. (2010) also raises the possibility of systematic biases in coupled model responses to external radiative forcing. SST information alone is inadequate to sort these issues out; diagnosis of the ocean's thermal stratification in the deeper column, the variability of currents and related transports, and time evolving surface fluxes spanning several decades will also be essential.

Such differences in SST trends between observations and simulations for 1977-2006, though generally less than $0.5^{\circ} \mathrm{C}$, nonetheless have major regional ramifications for precipitation trends. Figure 9 shows the vastly different regional precipitation patterns resulting from differences between observed versus CMIP3 simulated 1977-2006 SST conditions. Most notable in observations has been the drying trend during 1977-2006 occurring over a broad region of the eastern Pacific and adjacent continents including southwestern North America (Fig. 9, top). This feature is consistent with an influence of the oceans, as revealed by the results of atmospheric GCM simulations forced by the observed SSTs (Fig. 9, middle). However, this ocean influence is evidently not a feature of human-induced climate change, in so far as coupled ocean-atmosphere GCMs forced by GHG and aerosols fail to generate this wide spread-dryness (Fig. 9, bottom). It is likely that the trajectory of SSTs in the coming decades will continue to be a major factor determining which regions become unusually dry versus unusually wet and the challenge will be to improve the ocean observation system so as to support skillful SST predictions.

\section{OCEAN OBSERVATIONS AND DROUGHT PREDICTION}

Drought as a natural hazard often has severe, and long lasting societal impacts. This paper has given several examples of the impact of oceans on drought. It has attempted to show where ocean information and related observing systems are currently being used to render societal benefit via both drought attribution and drought early warning. By assessing the evidence for the ocean's role in drought on decadal and longer time scales, it also points to where new ocean observations may become valuable for advancing the frontier of climate attribution and prediction/projection efforts. This paper is not an exhaustive survey of the potential benefits of ocean information, and much of what is summarized herein focuses on the role of sea surface temperatures, though some inferences of other ocean information needs can be made.

It was shown that ocean observations in the tropical east Pacific, information that is vital to support predictions of ENSO, are tantamount to drought early warning over vast areas of the tropics and select midlatitude regions. Ocean information related to ENSO would also provide early warning for drought over the U.S. Southern Great Plains, although the evidence is not as strong as to whether skillful predictions of SSTs would serve to provide advance warning for drought in the U.S. Central to Northern Plains, a region devastated by drought during the 1930s. Strong evidence was found that Sahel drought of multi-decadal duration in the latter half of the $20^{\text {th }}$ Century was also SST influenced. And, several key regional features of rainfall trends during 19772006 were shown to be reconcilable with the particular observed trajectory of SSTs of the past 30-years. The observed trajectory of the oceans has, to date, deviated sufficiently from the simulated ocean response to anthropogenic forcing in the eastern Pacific Ocean to render materially different consequences for regional precipitation than anticipated from CMIP models. The challenge is to determine the physical processes involved in the observed ocean variability especially with a fidelity so that signatures of natural decadal variability can be discerned and distinguished from externally forced trends (e.g., Wang et al. 2009; Salomon et al. 2010).

Some clarity is emerging regarding the ocean information that would be needed to improve predictions of long and sustained drought. The U.S. climate sensitivity to prolonged cold states of the 

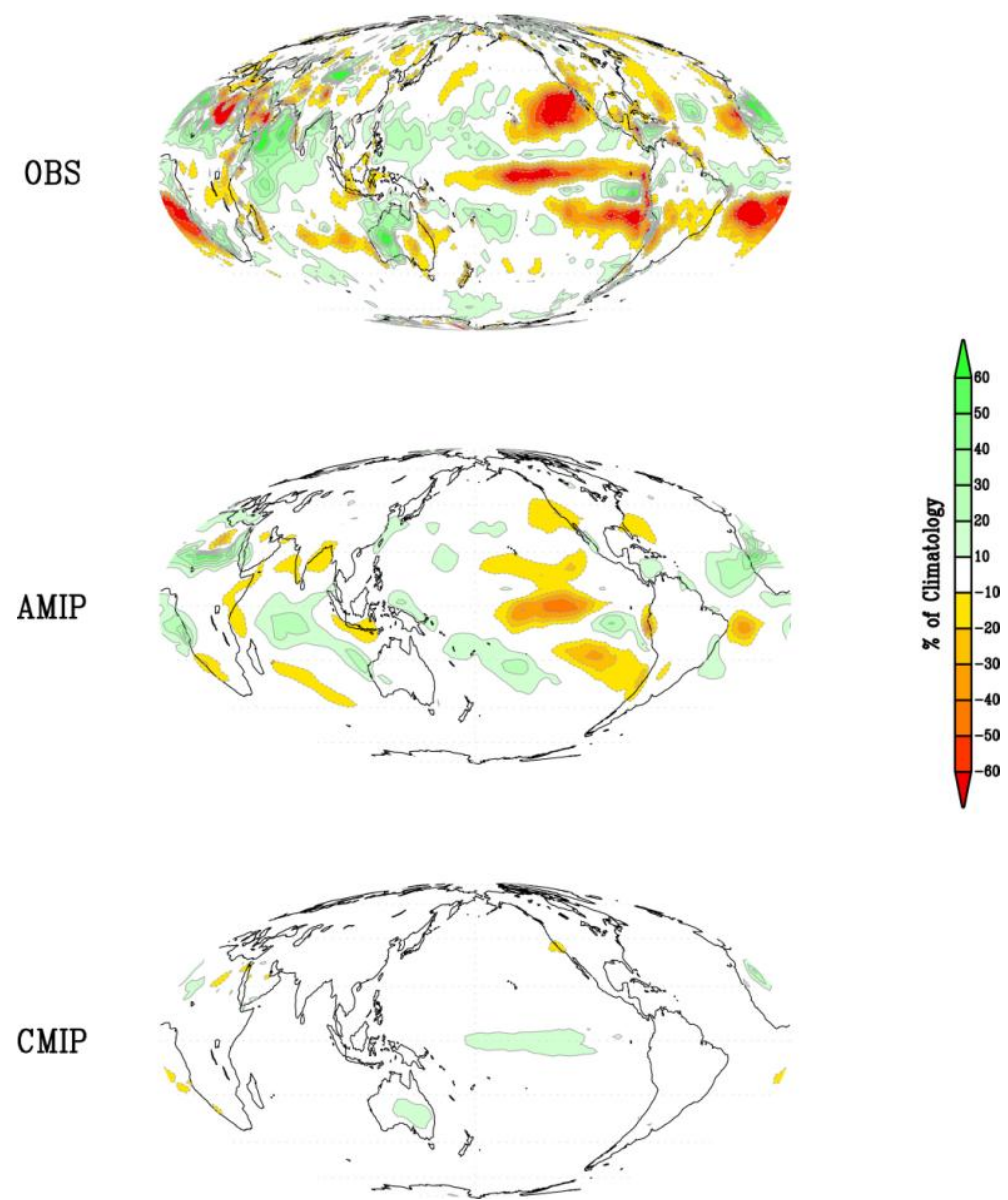

Figure 9. The observed (top), AMIP ensemble mean simulated (middle), and CMIP ensemble mean simulated (bottom) 30-year trends in annual precipitation during 1977-2006. AMIP simulations are based on an ensemble of 36 integrations of 4 different atmospheric models forced by the observed monthly varying SSTs, but using climatological GHGs. CMIP simulations are based on the average of 21 CMIP3 models that were forced by the observed G HG and aerosol variations from 1977-1999, and by the SRES A1B emissions scenario for 2000-2006.

tropical Pacific Oceans stands out as a particularly robust model feature, one that explains key aspects of 150 -years of observed drought variability over the southern Plains and southwestern U.S. The scientific understanding of this particular ocean-drought linkage is sufficiently advanced to promote a recommendation that a rigorous effort be made to assess the ocean observations required to support multi-annual to multidecadal predictions of tropical Pacific SSTs. A similar recommendation can be made to assess the ocean observations required to support multi-annual to decadal predictions of Atlantic basin SSTs, to which there is modest drought sensitivity over the U.S., but particularly strong drought sensitivity over the Sahel. Unlike the ENSO problem however, knowledge of the ocean observations required to make progress for decadal predictions is in its relative infancy [see Salomon et al. (2010) for an assessment of challenges in understanding decadal variability and predictability].
It should also be recognized that not all major droughts would be predicted even if perfect predictions of the ocean and sea surface temperature conditions were available. This point has been raised by Seager et. al. (2008) who concludes that prior knowledge of the SSTs could not have led to a skillful prediction of the central and northern Plains drought during the Dustbowl era. Despite this caveat, advance knowledge of tropical SSTs alone would have allowed a highconfidence prediction of a multiyear and severe drought, but one centered too far south and without strong cross-continental warming. Whether such differences are more related to fundamental limitations of existing models, shortcomings of the SST forcing specified in those models, or is due to a fundamental limit in the predictability of such drought is not currently resolved.

One of the critical attributes of ocean conditions as concerns drought risk over vast reaches of tropical and 
subtropical latitudes is the zonal contrast of SSTs between the warm pool of the Indio-west Pacific and the cold tongue of the equatorial east Pacific. Much has yet to be learned about the physical processes that control this zonal contrast and the processes that determine its multidecadal variability and change. This question is of high relevance for the $21^{\text {st }}$ Century projection of how rainfall patterns and their variability may change in the presence of anthropogenic forcing. It is by no means obvious whether the ocean observing system needed to support interannual to decadal prediction related to natural coupled variability would also have the required attributes to support the prediction/projection of the ocean's response to anthropogenic forcing. But to the extent that these two sources of drought variability are already comingling in the climate system today, a comprehensive assessment is required. In addition to the prediction requirements, climate-quality ocean observations are essential for distinguishing natural from humaninduced ocean conditions, and therefore are key in the accurate attribution of the causes of climate trends. Of particular importance is ensuring that natural variability, when occurring, is not misunderstood to indicate that climate change is either not happening or is happening more intensely than the true human influence.

Given the considerable persistence of SSTs on monthly to seasonal time scales, an obvious and core component to an ocean observing system for short term drought prediction is one that monitors the sea surface temperatures state globally. Such information is provided by in situ measurements from ocean vessels, buoys, and remotely by satellite radiometry. Ocean observing system requirements for capitalizing on potential predictability of decadal droughts are likely to differ from those needed to harvest seasonal drought predictability. For instance, information on the longer oceanic time scales such as may be reflected in the heat content in the upper few 1000 meters of the ocean, the slow variability of ocean transports, and perhaps even deeper ocean circulations that control the multi-decadal exchange of heat between the upper and lower ocean will become important. The field is poised on the precipice of new discoveries regarding oceans and climate as ocean data assimilation procedures advance and initialized decadal predictions of the coupled climate system begin in earnest during the coming years.

\section{REFERENCES}

1. Annamalai, H., P. Liu, and S-P. Xie, 2005: Southwest Indian Ocean SST Variability: Its Local Effect and Remote Influence on Asian Monsoons. J. Climate, 18, 4150-4167.

2. Bader, J., and M. Latif, 2003: The impact of decadalscale Indian Ocean sea surface temperature anomalies on Sahelian rainfall and the North Atlantic Oscillation. Geophys. Res. Lett., 30, doi:10.1029/2003GL018426.

3. Cook B. I., R. L. Miller, and R. Seager, 2008: Dust and sea surface temperature forcing of the 1930s "Dust Bowl" drought. Geophys Res Let, $t$ doi:10.1029/2008GL033486

4. Folland, C. K., T. N. Palmer, and D. E. Parker, 1986: Sahelian rainfall and worldwide sea temperatures 19011985. Nature, 320, 602-607.

5. Giannini, A., R. Saravanan, and P. Chang, 2003: Oceanic forcing of Sahel rainfall on interannual to interdecadal time scales. Science, 302, 1027-1030.

6. Goddard, L. and N. Graham, N. E., 1999: The importance of the Indian Ocean for simulating rainfall anomalies over eastern and southern Africa. J. Geophys. Res., 104, 19099-19116.

7. Hastenrath, S., 1984: Interannual variability and annual cycle: Mechanisms of circulation and climate in the tropical Atlantic sector. Mon. Wea. Rev., 112, 10971107.

8. Hastenrath, S., and K. Wolter, 1992: Large-scale patterns and long term trends of circulation variability associated with Sahel rainfall anomalies. J. Meteor. Soc. Japan, 70, 1045-1055.

9. Hoerling, M. P., and A. Kumar, 2003: The perfect ocean for drought. Science, 299, 691-694.

10. Hoerling, M., J. Hurrell, and J. Eischeid, 2006: Detection and attribution of $20^{\text {th }}$ Century northern and southern African rainfall change. J. Climate, 19, 3989-4008.

11. Hoerling, M., X. Quan, and J. Eischeid (2009), Distinct causes for two principal U.S. droughts of the 20th century, Geophys. Res. Lett., 36, L19708, doi:10.1029/2009GL039860.

12. Hoerling, M., J. Eischeid, and J. Perlwitz, 2010: Regional precipitation trends: Distinguishing natural variability from anthropogenic forcing. J. Climate, 23, 2131-2145.

13. Kiladis, G. N., and H. F. Diaz, 1989: Global climatic anomalies associated with extreme phases in the Southern Oscillation. J. Climate, 2, 1069-1090.

14. Koster, R. D., P. A. Dirmeyer, Z. Guo, and 22 others, 2004: Regions of strong coupling between soil moisture and precipitation. Science, 305, 1138-1140.

15. Lamb, P. J., 1978: Case studies of tropical Atlantic surface circulation patterns during recent Subsaharan weather anomalies: 1967 and 1968. Mon. Wea. Rev., 106, 482-491.

16. Lyon, B., 2006: Robustness of the influence of El Nino on the spatial extent of tropical drought. Advances in Geosciences, 6, 207-209.

17. McPhadden, M., and CoAuthors, 1998: The Tropical Ocean-Global Atmosphere observing system: A decade of progress. Journal of Geophysical Research, 103(C7), 14,169-14,240. 
18. Palmer, T. N., 1986: The influence of Atlantic, Pacific, and Indian Oceans on Sahel rainfall. Nature, 322, 251253.

19. Quan, X., M. Hoerling, J. Whitaker, G. Bates, and T. Xu, 2006: Diagnosing sources of U.S. seasonal forecast skill. J. Climate, 19, 3279-3293.

20. Ropelewski, C. F. and Halpert, M. S., 1987: Global and Regional Scale Precipitation Patterns Associated with the El Nino/Southern Oscillation, Mon. Wea. Rev., 115, $1606-1626$

21. Ropelewski, C. F. and Halpert, M. S, 1989 Precipitation patterns associated with the high index phase of the Southern Oscillation. J. Climate, 2, 268-284.

22. Schubert, S.D., M. J. Suarez, P. J. Pegion, R. D. Koster, and J. T. Bacmeister, 2004a: On the Cause of the 1930s Dust Bowl, Science, 33, 1855-1859.

23. Schubert, S.D., M. J. Suarez, P. J. Pegion, R. D. Koster, and J. T. Bacmeister, 2004b: Causes of long-term drought in the United States Great Plains. J. Clim., 17, 485-503.

24. Schubert, S.D., and Co-Authors, 2009: A U.S. CLIVAR Project to assess and compare the responses of global climate models to drought-related SST forcing patterns: Overview and results. J. Climate, 22, 5251-5272.

25. Seager, R., Y. Kushnir, C. Herweijer, N. Naik, and J. Velez, 2005: Modeling the tropical forcing of persistent droughts and pluvials over western North America: 1856-2000. J. Climate., 18, 4068-4091.

26. Seager, R., Y. Kushnir, M. Ting, M. Cane, N. Naik and J. Miller, 2008: Would advance knowledge of 1930s SSTs have allowed prediction of the Dust Bowl drought? J. Climate, 21, 3261-3281.

27. Solomon, A., and Co-Authors, 2010: Distinguishing the roles of natural and anthropogenically forced decadal climate variability: Implications for prediction. Bull. Amer. Meteor. Soc., conditionally accepted.

28. Wang, H., S.D. Schubert, M. J. Suarez, J. Chen, M. Hoerling, A. Kumar and P. Pegion, 2009: Attribution of the seasonality and regionality in climate trends over the United States during 1950-2000., J. Climate, 25712590, 2009. 